\title{
Determination of Dynamic Plasma Thiol -disulfide Homeostasis with a Novel Technique in Intestinal Ischemia Reperfusion Injury
}

\author{
Ersin Gürkan Dumlu, Mehmet Tokaç, Mustafa Özsoy, İbrahim Kılınç, Nazmiye Dinçer, \\ Özcan Erel, and Mehmet Kılıç
}

\section{ABSTRACT}

Introduction: Intestinal ischemia/reperfusion (I/R) is a serious lifethreatening clinical case. Overproduction of reactive oxygen species (ROS) associated with oxidative stress plays a key role in $I / R$ pathophysiology.

Objective: The aim of this study is to evaluate dynamic thiol / disulfide hemostasis in intestinal $I / R$ in rats.

Materials and Methods: 24 Winstar albino rats were divided into 3 groups (8 animals in each group: (1) sham (operation without ischemia), (2) ischemia (90 minutes ischemia), (3) ischemia/reperfusion (after ischemia for 30 minutes reperfusion for 60 minutes). At the end of the process, liver samples were evaluated pathologically. Also, in plasma samples, native thiol, disulphide and total thiol levels were measured.

Results: Native thiol levels in ischemia and I/R group were found to be significantly lower compared to the sham group $(\mathbf{P}<0.001)$. Disulfide levels in Ischemia group were found to be significantly higher compared to the sham group $(P<0.05)$. Disulfide / native thiol levels in ischemia and $I / R$ group were found to be significantly higher compared to the sham group $(P<0.05)$. Disulfide / total thiol levels in both ischemia and I/R group were found to be significantly higher compared to the sham group ( $P<$ 0.05).

Conclusion: Balance of dynamic thiol/disulfide is a quite suitable indicator for evaluating oxidative stress which occurs as a result of intestinal I/R. As a result, measurement of dynamic thiol/disulfide balance with Erel method is fully automated and practical for evaluating oxidative environment which is formed with ischemia reperfusion.

Keywords: thiol, disulfide, thiol / disulfide hemostasis, intestinal ischemia.

Published Online: June 23, 2021

ISSN: $2736-5476$

DOI: $10.24018 /$ ejclinicmed.2021.2.3.ID

\section{Ersin Gürkan Dumlu*}

Department of General Surgery, Faculty of Medicine, Yildırım Beyazıt University, Ankara, Turkey.

(e-mail: gurkandumlu@gmail.com) Mehmet Tokac

Department of General Surgery, Faculty of Medicine, İstinye University, İstanbul, Turkey.

Mustafa Özsoy

Department of General Surgery, Faculty

of Medicine, Yildırım Beyazıt

University, Ankara, Turkey.

İbrahim Kılınç

Department of General Surgery, Atatürk Bilkent City Hospital, Ankara, Turkey.

Nazmiye Dinçer

Department of Pathology, Ankara Bilkent City Hospital, Ankara, Turkey.

Özcan Erel

Department of General Biochemistry,

Faculty of Medicine, Yıldırım Beyazıt

University, Ankara, Turkey.

Mehmet Kilıc

Department of General Surgery, Faculty of Medicine, Yildırım Beyazit University, Ankara, Turkey.

*Corresponding Author

\section{INTRODUCTION}

Intestinal ischemia-reperfusion (I/R) is a common condition that is observed in cases like mesenteric ischemia, abdominal aortic aneurysm, trauma, and severe burns. In tissue injury, there is contribution of reperfusion followed by ischemia not only of ischemia [1]. Unlike the case of ischemic injury, in the case of reperfusion, damage does not only occur in the affected area but may also occur in distant organs and throughout the body systemically. This damage is induced by reactive oxygen and nitrogen radicals, microvascular damage, inflammatory cytokines and complement system [2]. In addition to rupture of the mucosal barrier, bacterial translocation, and activation of inflammatory response; acid-base balance disorder may also be observed [3]. This damage which occurs in distant organs is referred to as post-traumatic multiple organ failure [4].
Related with oxidative stress, overproduction of Reactive Oxygen Species (ROS) plays a key role in the pathophysiology of I/R (3). ROS are the oxidation and reduction agents which can cause damage directly in cell membrane through lipid peroxidation [5]. ROS is normally cleared by antioxidant enzymes such as superoxide dismutase (SOD) and glutathione peroxidase (GPx). However, when ROS production reaches very high levels, oxidative stress occurs. The most common ROS are superoxide, hydrogen peroxide, singlet oxygen, and hydroxyl radicals. The dominance of this reagent products can cause damage in DNA as well as all macromolecules comprising proteins and lipids [6]. While protein carbonyl content (PCO) increases by oxidation of proteins, MDA also increases as the secondary product of lipid peroxidation [7], [8]. At the same time, peroxidation of endogenous lipid causes the transformation of reduced glutathione (GSH), a 
non-enzymatic intracellular antioxidant, to glutathione disulfide (GSSG) [9], [10].

The thiols which are called mercaptans since they bind mercury are sulfhydryl (-SH) containing organic compounds which are formed by bonding of sulphur and hydrogen atoms to carbon atom [11]. Thiols (RSH) can undergo oxidation reaction by the oxidants and disulfide (RSS) bonds can be formed. The resulting disulfide bond can be reduced to thiol groups again, so that the dynamic thioldisulfide hemostasis is continued [12]. Dynamic thiol/disulfide equilibrium condition plays a critical role in terms of antioxidant defense, detoxification, apoptosis, trancription in the regulation of enzyme activity and cellular signal transduction mechanisms. Until recently, plasma/serum thiol levels were measured widely by Ellman method, there was not a method available which measures the plasma thiol/disulfide balance colorimetrically. Erel et al. for the first time developed a colorimetric, exactly automated method to measure plasma dynamic thiol/disulfide levels [12].

Our aim in this study is to determine dynamic thiol/disulfide balance with this new method in intestinal ischemia reperfusion model.

\section{MEterial AND METHODS}

\section{A. Study Design and Ethics}

This was a prospective, randomized, controlled, experimental animal study. This study was approved by the Ethics Committee for Animal Experiments and all animal experients were carried out in accordance with Guide for the Care and Use of Laboratory Animals issued by the US National Research Council Committee and local requirements [14].

\section{B. Animals and Experimental Procedure}

In this study, 24 300-350 g weighing Winstar albino rats were used. Three days before the experiment, rats were maintained in cages which had appropriate room temperature and humidity, and which had access to water and standard ad libitum. All surgical procedures were performed under intramuscular xylazine $(5 \mathrm{mg} / \mathrm{kg}$ xylazine hydrochloride, Rompun, Bayer Chemical) and ketamine (50 $\mathrm{mg} / \mathrm{kg}$ ketamine hydrochloride, Ketamine, Parke-Davis) anesthesia. Heart rate was monitored during the procedure. All rats were divided randomly into 3 groups of 8 animals in each group.

\section{Sham}

In this group, midline laparotomy was performed on the abdominal wall after cleaning it with $10 \%$ povidone-iodine. The superior mesenteric artery was dissected but an additional procedure was not performed. Two $\mathrm{ml}$ of serum physiological was given in the abdomen. After that, peritoneum and abdominal wall was closed with $3 / 0$ silk suture. Rats in this group were sacrificed after 90 minutes by opening the seams and collecting intracardiac blood samples.

\section{Ischemia}

After performing laparotomy in this group, superior mesenteric artery was clamped by atraumatic clamp. Mesenteric ischemia was verified with the absence of mesenteric pulsations and paleness of the intestinal segment. Two $\mathrm{ml}$ of serum physiological was given in the abdomen. After that, peritoneum and abdominal wall was closed with $3 / 0$ silk suture. Rats in this group were sacrificed after 90 minutes by opening the seams and collecting intracardiac blood samples.

\section{Ischemia-reperfusion $(I / R)$}

After performing laparotomy, superior mesenteric artery was clamped by atraumatic clamp. Two $\mathrm{ml}$ of serum physiological was given in the abdomen. After that, peritoneum and abdominal wall was closed with $3 / 0$ silk suture. After 30 minutes, relaparotomy was performed and microvascular clamp was removed. Mesenteric reperfusion was confirmed by pulsation and return of color. Abdomen layers were again closed with $3 / 0$ silk suture. Rats in this group were sacrificed after 60 minutes by opening the seams and collecting intracardiac blood samples.

Body temperature of rats were maintained at $37{ }^{\circ} \mathrm{C}$ throughout the entire procedure. At the end of the study nearly $4 \mathrm{ml}$ blood samples were collected into heparinized tube. Approximately $5 \mathrm{~cm}$ ileum samples were taken from the rats for pathological examination.

\section{Thiol/Disulfide Measurement}

These measurements were performed by using the method of Erel et al. [12]. Dynamic disulphide bonds ( $-\mathrm{S}-\mathrm{S}-)$ in the sample are reduced to functional thiol groups $(-\mathrm{SH})$ by $\mathrm{NaBH} 4$. The unused $\mathrm{NaBH} 4$ remnants are completely removed by formaldehyde. Thus, this prevents the extra reduction of the DTNB and further reduction of the formed disulphide e bond, which are produced after the DTNB reaction. The total thiol content of the sample is measured using modified Ellman reagent. Native thiol content is subtracted from the total thiol content and half of the obtained difference gives the disulphide e bond amount.As a result, native thiol $(-\mathrm{SH})$, disulphide $(-\mathrm{S}-\mathrm{S}-)$ and total thiol $(-\mathrm{SH}+-\mathrm{S}-\mathrm{S}-)$ amounts, $-\mathrm{S}-\mathrm{S}-/-\mathrm{SH},-\mathrm{S}-\mathrm{S}-/(-\mathrm{SH}+-$ $\mathrm{S}-\mathrm{S}-), \quad-\mathrm{SH} /(-\mathrm{SH}+-\mathrm{S}-\mathrm{S}-)$ ratios were calculated automatically and synchronously.

\section{Pathological Evaluation}

Ileum specimens were fixed in $10 \%$ neutral formalin, embedded in paraffin and sectioned into 5- $\mu \mathrm{m}$ slices. Sections were stained with hematoxylin and eosin, and histologic architecture was graded on a 6- tiered scale defined by Chiu's classification [15]: 0, normal villi; 1 , villi with tip distortion; 2, Guggen- heim's spaces; 3, villi with patchy disruption of the epithelial cells; 4, villi with exposed but intact lamina propria with epithelial sloughing; 5, exuding lamina propria; 6 , hemorrhaged or denuded villi.

\section{E. Statistics}

Statistical analysis was performed using SPSS 20.0 software. The characteristics of the groups were summarized with basic statistics. Mean, standard deviation, median, minimum, and maximum values were used to summarize the numerical parameters. The distribution of the groups was tested by the Shapiro-Wilk test. Groups with normal distribution were compared using ANOVA. Secondary comparisons were made with post-hoc turkey test. The cases that show skewed distribution were compared with the Kruskal-Wallis test. Secondary comparisons were 
performed using the Mann-Whitney U test with Bonferroni correction. Statistical significance level was determined as $\mathrm{P}$ $<0.05$.

\section{RESULTS}

\section{A. Thiol / Disulfide Hemostasis}

Native thiol, disulfide, total thiol levels were shown in Table I. Native thiol levels in ischemia and I/R group were significantly lower compared to the sham group $(\mathrm{P}<0.001)$. Disulfide levels in ischemia group were significantly higher compared to the sham group $(\mathrm{P}<0.05)$. If total thiol levels are evaluated, a significant decrease was observed in $I / R$ group compared to the sham group while there was no significant difference between ischemia group and other groups.

The results found from the rates between the parameters are shown in Table II. $-\mathrm{S}-\mathrm{S}-/-\mathrm{SH}$ ratios in ischemia and I/R group were significantly higher compared to the sham group $(\mathrm{P}<0.05)$. -S-S-/(-SH + -S-S-) levels in both ischemia and $\mathrm{I} / \mathrm{R}$ groups were significantly higher compared to the sham group ( $\mathrm{P}<0.05)$. If $-\mathrm{SH} /(-\mathrm{SH}+-\mathrm{S}-\mathrm{S}-)$ ratios is evaluated, ischemia and I/R group was significantly higher compared to the sham group $(\mathrm{P}<0.001)$.

\begin{tabular}{ccccc}
\multicolumn{5}{c}{ TABLE I: NATIVE THIOL, DISUlPHIDE, TOTALY THIOL LEVELS OF EXPERIMENTAL GROUPS } \\
\hline & Sham & İskemi & İskemi/reperfusion & $\mathrm{p}$ \\
\hline$-\mathrm{SH}(\mu \mathrm{mol} / \mathrm{L})$ & $192 \pm 2.75 \pm 48.52$ & $100.00 \pm 42,21^{\mathrm{a}}$ & $84.38 \pm 29.89^{\mathrm{a}}$ & $<0.001$ \\
$-\mathrm{S}-\mathrm{S}-(\mu \mathrm{mol} / \mathrm{L})$ & $53.75 \pm 12.79$ & $72.81 \pm 10.67^{\mathrm{a}}$ & $64.12 \pm 10.78$ & 0.031 \\
$-\mathrm{SH}+-\mathrm{S}-\mathrm{S}-$ & $300.25 \pm 38.35$ & $257.88 \pm 48,07$ & $212.63 \pm 34.12^{\mathrm{a}}$ & 0.001 \\
$(\mu \mathrm{mol} / \mathrm{L})$ & & &
\end{tabular}

Oneway Varriance (ANOVA), ${ }^{\mathrm{a}} \mathrm{p}<0.05$ vs sham, $-\mathrm{SH}$ : native thiol, $-\mathrm{S}-\mathrm{S}-$ : disulphide, $-\mathrm{SH}+-\mathrm{S}-\mathrm{S}-$ : totaly thiol.

TABLE II: NATIVE THIOL, DisulPHIDE, TOTALY THIOL LEVELS RATIOS OF EXPERIMENTAL GROUPS

\begin{tabular}{ccccc}
\hline & Sham & İskemi & İskemi/reperfusion & $\mathrm{p}$ \\
\hline$-\mathrm{S}-\mathrm{S}-/-\mathrm{SH}$ & $0.39(0.14-0.54)$ & $0.65(0.40-0.89)^{\mathrm{c}}$ & $0.61(0.48-0.78)^{\mathrm{c}}$ & $0.002^{\mathrm{b}}$ \\
$\mathrm{S}-\mathrm{S}-/(-\mathrm{SH}+-\mathrm{S}-\mathrm{S}-)$ & $0.18 \pm 0.06$ & $0.32 \pm 0.18^{\mathrm{c}}$ & $0.30 \pm 0.05^{\mathrm{c}}$ & $0.001^{\mathrm{a}}$ \\
$-\mathrm{SH} /(-\mathrm{SH}+-\mathrm{S}-\mathrm{S}-)$ & $0.63 \pm 0.12$ & $0.37 \pm 0.12^{\mathrm{c}}$ & $0.39 \pm 0.10^{\mathrm{c}}$ & $<0.001^{\mathrm{a}}$ \\
\hline
\end{tabular}

${ }^{\mathrm{a} O n e w a y V a r r i a n c e}$ (ANOVA) ${ }^{\mathrm{b}}$ Kruskal Wallis test ${ }^{\mathrm{c}} \mathrm{p}<0,05$ vs sham.

$-\mathrm{S}-\mathrm{S}-/-\mathrm{SH}$ : disulphide e /native thiol, $\mathrm{S}-\mathrm{S}-/(-\mathrm{SH}+-\mathrm{S}-\mathrm{S}-)$ : disulphide e/ totaly thiol.

\section{B. Pathological Findings}

Patology specimens obtained from the sham group were evaluated as normal. In ischemia and I/R groups, mostly villi with patchy disruption of the epithelial cells (Grade 3) and villi with epitelial sloughing which has intact lamina propria (Grade 4) was detected.

\section{DiscUSSION}

Intestinal ischemia is a difficult clinical situation to struggle with for clinicians due to the difficulty of early diagnosis and high mortality rates. For this reason, pathophysiology, effects, and treatment strategies of intestinal I/R damage still continues to be widely discussed through experimental work [16], [17]. Widely discussed subjects in these studies are to reduce $I / R$ damage with various drugs and antioxidants and to increase the vitality at the cells. However, there is no medical treatment protocol that has been clinically used.

Intestinal ischemia occurs with completely blocked or severely reduced intestinal blood flow. Although precise mechanism of damage is unknown, the studies have shown that infiltration of polymorphonuclear leukocyte, proinflamatuar cytokines and formed oxidative stress play a major role in this damage [18]. Various parameters are being used for evaluation of oxidative stress in intestinal I/R. MDA, which is the secondary product of lipid peroxidation is one of the most frequently used parameters. Tuncer et al. have evaluated the effect of of antioxidant agents containing sulfhydryl in intestinal I/R damage. In this study, MDA, and protein carbonyl content (PCO) levels in $\mathrm{I} / \mathrm{R}$ group were higher than the control group [6]. Karakas et al. have evaluated the effect of luteolin on total oxidant status (TOS), total antioxidant capacity (TAC) and oxidative stress index on intestinal $\mathrm{I} / \mathrm{R}$ formed rats. In this study, mucosal TOS levels increased significantly in I/R group compared to the sham group, and a significant decrease in TAC capacity have been identified [19]. Superoxide dismutase (SOD) activity is another parameter used for evaluation of intestinal I/R damage. While Sizlan et al. [20] have found that SOD activity has increased with I/R; Yucel et al. [21] have found decrease in SOD activity.

In oxidative environment, peroxidation of lipids causes the oxidation of GSH, which is a non-enzymatic intracellular antioxidant, to GSSG [9]. GSH/GSSG ratio is another parameter used for evaluation of oxidative damage which is result of $I / R$. In a study evaluating the effect of mesna on intestinal $\mathrm{I} / \mathrm{R}$ damage, it is found that jejuna mucosa GSH/GSSG ratio was significantly lower in $\mathrm{I} / \mathrm{R}$ group compared to the sham group [22]. Suyavar an et al., in their study have evaluated the role of GSH treatment of young and old rats on hepatik I/R model. In this study, serum, mitochondrial and cytosolic GSH levels in hepatic I/R group have been shown to be significantly low compared to the sham group. GSSG levels were not significantly different between the groups [23]. While in the same study GSH/GSSG ratio of I/R group was significantly lower compared to the sham group; in the group treated with $\mathrm{GSH}$, this rate was restored and found to be similar to the sham group.

While plasma thiol pool is largely composed of albumin and other proteins, a small portion of it is composed of low molecular weight thiols like cysteine, cysteinylglycine, glutathione, homocysteine and $\gamma$-glutamilsiste [24]. Thiol groups of the proteins, thiol groups of low molecular weight compounds and cysteine residues are converted to disulfide bond structures as a result of oxidation by the oxidant molecules [12]. 
The resulting disulfide bond scan again be reduced to the thiol groups and thus thiol disulphide e balance is maintained [12]. Dynamic thiol/disulfide balance condition has critical roles in antioxidant defense, detoxification, apoptosis, transcription in the regulation of enzyme activity and cellular signal transduction mechanisms [13].

As mentioned above, in previous studies, low molecular thiol source measurements, that constitute a small portion of the thiol pool, such as Cys, CySS, GSG and GSSG were used in order to define the amount of thiol disulfide amounts [25], [26]. Erel et al. [12], in their study, have used thiol containing GSH, 2-mercaptoethonol, albumin solution and plasma samples in order to measure thiol-disulfide exchange reaction, with the new method they have developed. In this study, each sample was exposed to serially increasing doses of oxidative agents $\left(\mathrm{H}_{2} \mathrm{O}_{2}\right)$. Prior to oxidation native thiol levels were measured and with the addition of oxidizing agents it is found that native thiol levels decreased linearly while disulfide rates increased. In this study, while levels of oxidants showed a positive correlation with disulfide levels it showed negative correlations with native thiol levels and total thiol levels did not change with doses of oxidant levels. GSH and its oxidated form GSSG are incomplete parameters of thiol-disulfide homeostasis but native thiol including GSH and disulfide including GSSG measurement provide total hemostatic evaluation. Additionally, the result can be achieved automatically in 10 minutes like blood glucose measurement.

There is not a study which measures plasma dynamic thiol disulfide balance for evaluation of I/R damage. Unlike previous studies, in this study we have evaluated plasma dynamic thiol/disulfide hemostasis by measuring native thiol and disulfide levels in I/R damage. When the results are analyzed, oxidative stress formed in $I / R$ and ischemia groups found to cause a significant decrease in native thiol (-SH) levels. In parallel, especially in ischemia group, increases were detected in disulfide levels (-SS). This indicates that in oxidative environment, $-\mathrm{SH}$ groups of the molecules formed $-\mathrm{SS}-$ groups with oxidation. When the rates of disulfide levels to native thiol and total thiol amounts are evaluated, significant increases are seen in $I / R$ and ischemia groups. This result is a strong indication of the dominance of oxidative environment in $\mathrm{I} / \mathrm{R}$ and ischemia groups.

\section{CONCLUSION}

As a result, measurement of dynamic thiol/disulfide balance with Erel method is fully automated and practical for evaluating oxidative environment which is formed with ischemia reperfusion. In addition, we believe that dynamic balance measurement will be advantageous for assessing the effects of drugs and antioxidant agents used to prevent this damage and will provide a great contribution to future work.

\section{REFERENCES}

[1] Mallick IH, Yang W, Winslet MC, Seifalian AM. İskemi-reperfusion injury of the intestine and protective strategies against injury. Dig Dis Sci. 2004; 49: 1359-77.

[2] Carden DL, Granger DN. Pathophysiology of ischaemia-reperfusion injury. J Pathol. 2000; 190: 255-66.
[3] Parks DA, Granger DN. Contributions of iskemi and reperfusion to mucosal lesion formation. Am J Physiol 1986; 250: G749-G753.

[4] Cerqueira NF, Hussni CA, Yoshida WB. Pathophysiology of mesenteric iskemi/reperfusion: a review. Acta Cir Bras 2005; 20: 336343.

[5] Nunomura A, Castellani RJ, Zhu X, Moreira PI, Perry G, Smith MA. Involvement of oxidative stress in Alzheimer disease. J Neuropathol Exp Neurol 2006; 65: 631-641.

[6] Tunc T, Oter S, Güven A, Topal T, Kul M, Korkmaz A, Ongürü O, Sarici U. Protective effect of sulfhydryl-containing antioxidants against iskemi/reperfusion injury of prepubertal rat intestine. J Gastroenterol Hepatol. 2009; 24: 681-7.

[7] Tokaç M, Taner G, Aydın S, Ozkardeş AB, Dündar HZ, Taşlıpınar MY, Arıkök AT, Kılıç M, Başaran AA, Basaran N Protective effects of curcumin against oxidative stress parameters and DNA damage in the livers and kidneys of rats with biliary obstruction. Food Chem Toxicol. 2013; 61: 28-35.

[8] Levine RL, Garland D, Oliver CN, Amici A, Climent I, Lenz AG, Ahn BW, Shaltiel S, Stadtman ER. Determination of carbonyl content in oxidatively modified proteins. Methods Enzymol. 1990; 186: 46478.

[9] Adams JD Jr, Lauterburg BJ, Mitchell JR. Plasma glutathione and glutathione disulfide in the rat: Regulation and response to oxidative stress. J Pharmacol Exp Ther 1983; 227:749.

[10] Briviba K, Sies H. Non enzymatic antioxidant defense system. In: Frei B, ed. Natural antioxidants in human health and dis- ease. San Diego: Academic Press, 1994:107-128.

[11] Sen CK, Packer L.Thiol homeostasis and supplements in physical exercise. Am J Clin Nutr. 2000; 72: 653S-69S.

[12] Erel O, Neselioglu S A novel and automated assay for thiol/disulphide e homeostasis. Clin Biochem. 2014; 47: 326-32.

[13] Circu ML, Aw TY. Reactive oxygen species, cellular redox systems, and apoptosis. Free Radic Biol Med. 2010; 48: 749-62.

[14] National Research Council (US) Committee for the Update of the Guide for the Care and Use of Laboratory Animals. Guide for the Care and Use of Laboratory Animals. 8th ed. Washington (DC): National Academies Press (US); 2011.

[15] Slone EA, Rope MR, Roth M, Welti R, Fleming SD. TLR9 is dispensable for intestinal iskemi/reperfusion-induced tis- sue damage. Am J Clin Exp Immunol 2012; 1: 124-135.

[16] Dumlu EG, Bozkurt B, Tokaç M, Kiyak G, Ozkardeş AB, Ergin M, Yazgan A, Kılıç M. Oxidative Stress and Lipid Peroxidation in the Ischemic Small Intestine: Pathological and Biochemical Evaluation in a Rat model of Superior Mesenteric Ischemia. Int Surg. 2014; 99: 868-74.

[17] Boybeyi Ö, Gunal YD, Atasoy P, Kisa U, Aslan MK The effect of colchicine and low-dose methotrexate on intestinal iskemi/reperfusion injury in an experimental model. J Pediatr Surg. 2014; 49: 1471-4.

[18] Zabot GP, Carvalhal GF, Marroni NP, Hartmann RM, da Silva VD, Fillmann HS. Glutamine prevents oxidative stress in a model of mesenteric iskemi and reperfusion. World J Gastroenterol. 2014; 20: 11406-14.

[19] Karakaş BR, Davran F, Elpek GÖ, Akbaş SH, Gülkesen KH, Bülbüller N. The effects of luteolin on the intestinal iskemi/reperfusion injury in mice.J Invest Surg. 2014; 27: 249- 255.

[20] Sizlan A, Guven A, Uysal B, Yanarates O, Atim A, Oztas E, Cosar A, Korkmaz A. Proanthocyanidin protects intestine and remote organs against mesenteric iskemi/reperfusion injury.World J Surg. 2009; 33: 1384-91.

[21] Yucel AF, Kanter M, Pergel A, Erboga M, Guzel A. The role of curcumin on intestinal oxidative stress, cell proliferation and apoptosis after iskemi/reperfusion injury in rats. J Mol Histol. 2011; 42: 579-87.

[22] Ypsilantis P, Lambropoulou M, Anagnostopoulos C, Tentes I, Tsigalou C, Pitiakoudis M, Kortsaris A, Papadopoulos N, Simopoulos C. Mesna preserves hepatocyte regenerating capacity following liver radiofrequency ablation under Pringle maneuver.J Surg Res. 2011; 169: 44-50.

[23] Suyavaran A, Ramamurthy C, Mareeswaran R, Subastri A, Lokeswara Rao P, Thirunavukkarasu C. TNF- $\alpha$ suppression by glutathione preconditioning attenuates hepatic iskemi reperfusion injury in young and aged rats. Inflamm Res. 2015; 64(1): 71-81.

[24] Turell L, Radi R, Alvarez B. The thiol pool in human plasma: the central contribution of albumin to redox processes. Free Radic Biol Med. 2013; 65: 244-253.

[25] Głowacki R, Bald E. Fully automated method for simultaneous determination of total cysteine, cysteinylglycine, glutathione and homocysteine in plasma by HPLC with UV absorbance detection. J Chromatogr B Analyt Technol Biomed Life Sci. 2009; 877: 34003404. 
[26] Carru C, Deiana L, Sotgia S, Pes GM, Zinellu A Plasma thiols redox status by laser-induced fluorescence capillary electrophoresis.. Electrophoresis. 2004; 25: 882-889. 